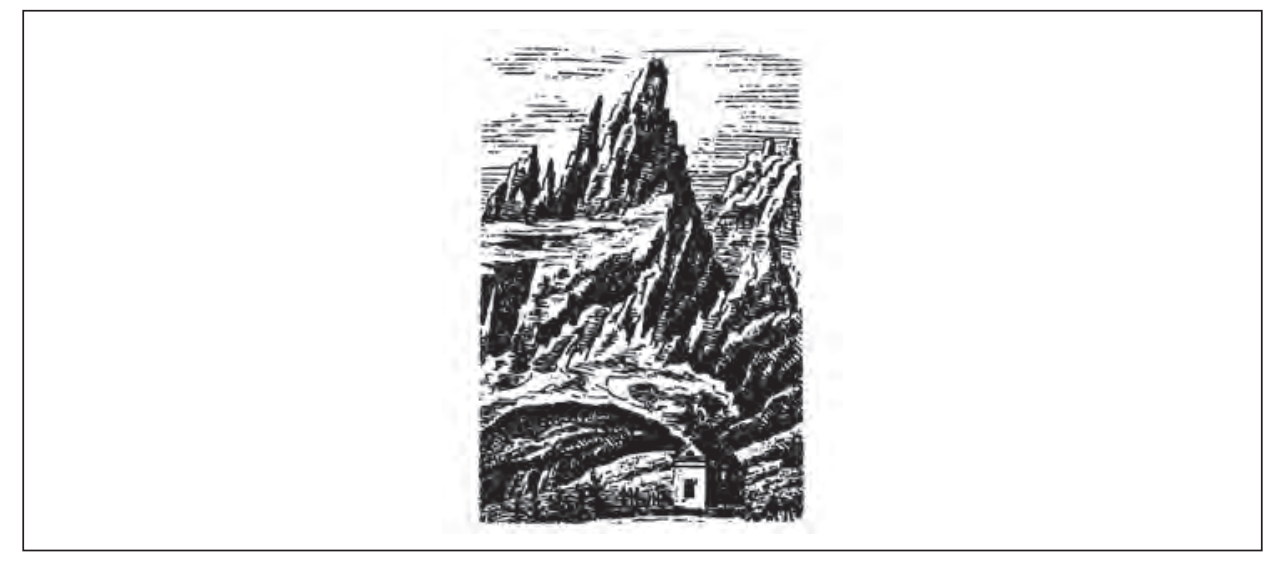

Ewa Grzęda

ORCID: 0000-0001-5254-9458

Uniwersytet Wrocławski

ewa.grzeda@uwr.edu.pl

ewagrzeda@02.pl

https://doi.org/10.19195/2084-4107.13.28

\title{
XXIV Festiwal Górski im. Andrzeja Zawady - statuetki za popularyzacje kultury górskiej
}

24th Andrzej Zawada mountain festival — statuettes for popularizing mountain culture

Słowa-klucze: Lądek-Zdrój, popularyzacja kultury górskiej, festiwal górski, Złote Czekany Keywords: Lądek-Zdrój, popularisation of mountain culture, mountain festival, Piolet d'Or

XXIV Festiwal Górski im. Andrzeja Zawady w Lądku-Zdroju (19-22 września 2019 roku) obfitował w wiele niezwykłych wydarzeń. Po raz drugi kulminacyjnym punktem festiwalowego programu była ceremonia wręczenia Złotych Czekanów (Les Piolets d'Or); jest to impreza rangi światowej. Jak piszą autorzy przewodnika festiwalowego: 


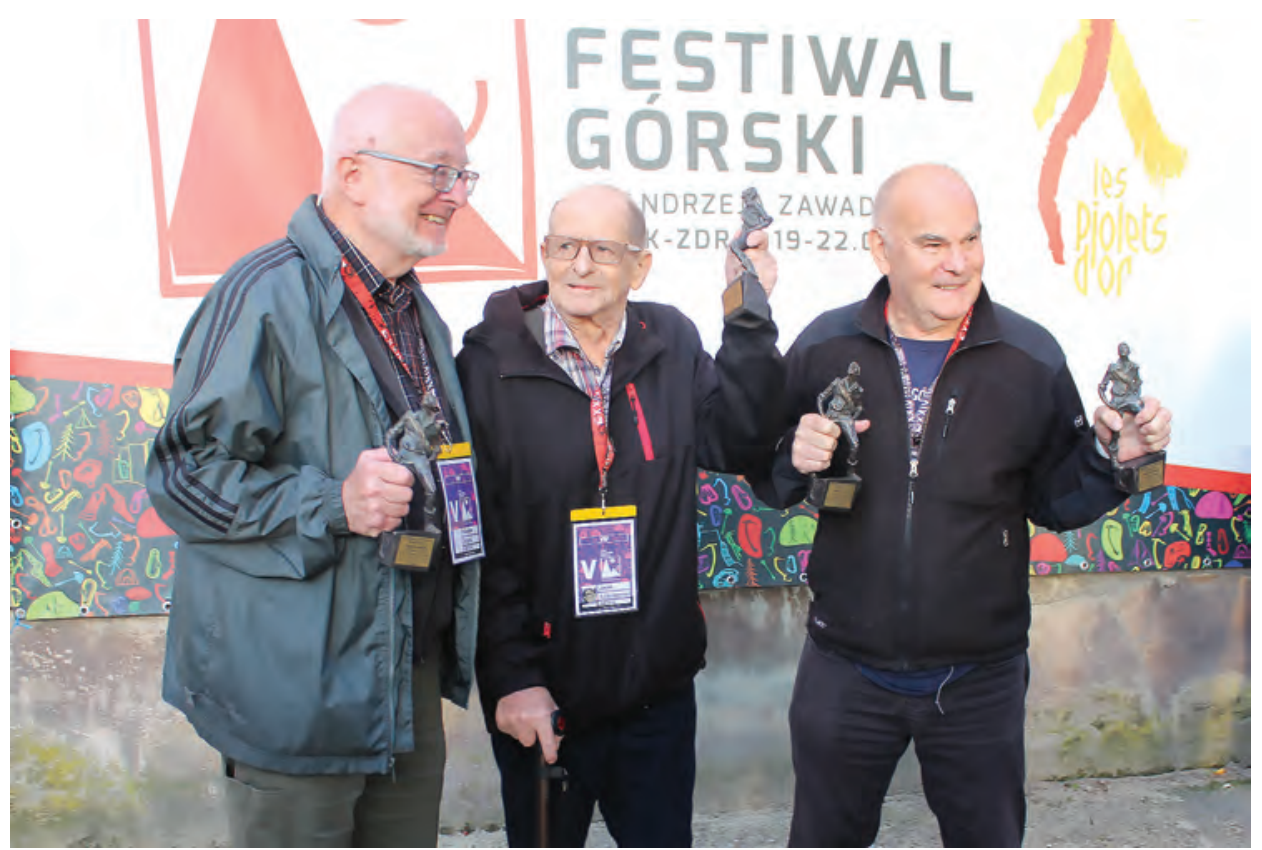

1. Laureaci nagród za popularyzację kultury górskiej, Festiwal Górski im. Andrzeja Zawady, Lądek-Zdrój 2019, fot. Ewa Grzęda

Celem Złotych Czekanów jest popularyzowanie wiedzy o największych alpinistycznych osiągnięciach. Zadaniem, jakie postawili przed sobą organizatorzy, jest celebrowanie ducha przygody i eksploracji oraz odwagi, których wymaga sztuka wspinania się w stylu alpejskim na dużych ścianach w górach wysokich. Złote Czekany są świętem górskiego partnerstwa i solidarności, czerpiąc inspirację z bogatej historii alpinizmu ${ }^{1}$.

Podczas festiwalowej gali Les Piolets d'Or (2019) Złoty Czekan za całokształt osiągnięć w górach wysokich odebrał Krzysztof Wielicki. W gronie laureatów nagrodzonych Złotym Czekanem znaleźli się także: Aleš Česen, Luka Stražar, Tom Livingstone oraz pośmiertnie David Lama i Hansjörg Auer. Galę poprzedziła wzruszająca uroczystość wręczenia Orderów Legii Honorowej (L'Ordre national de la Légion d'honneur) trzem członkom czteroosobowego zespołu, który w styczniu 2018 roku przeprowadził akcję ratunkową na Nanga Parbat, sprowadzając $\mathrm{w}$ niezwykle trudnych zimowych warunkach $\mathrm{z}$ ośmiotysięcznika mocno osłabioną i kontuzjowaną Elisabeth Revol. Himalaiści: Adam Bielecki, Jarosław Botor i Denis Urubko przyjęli najwyższe odznaczenia nadawane przez państwo francuskie z rąk ambasadora Francji Pierre’a Lévy’ego. Piotr Tomala

\footnotetext{
${ }^{1}$ XXIV Festiwal Górski im. Andrzeja Zawady, Ladek Zdrój 19-22.09.2019, [b.m.w.] 2019,
} s. 19. 
(czwarty członek zespołu ratunkowego) Order Legii Honorowej odebrał osobiście w ambasadzie Francji w Warszawie wcześniej (13 lipca 2019 roku).

Podczas osobnej gali festiwalowej wręczono także statuetki za popularyzację kultury górskiej, przyznawane od 2013 roku przez organizatorów Festiwalu, czasopismo „Taternik” oraz Polski Związek Alpinizmu osobom szczególnie zasłużonym w promowaniu gór i działań górskich. W tym roku uhonorowano w ten sposób Jacka Kolbuszewskiego — założyciela i pierwszego redaktora rocznika „Góry - Literatura - Kultura”, Janusza Majera i współpracującego z Pracownią Badań Humanistycznych nad Problematyką Górską Wiesława Aleksandra Wójcika. Serdecznie gratulujemy wszystkim laureatom.

\section{Laureaci nagrodzeni wyróżnieniem za popularyzację kultury górskiej 2019}

Jacek Kolbuszewski - profesor zwyczajny w zakresie historii literatury polskiej i literatur zachodniosłowiańskich, od ponad pół wieku zajmuje się tematyką górską w literaturze i kulturze w szerokim zakresie geograficznym (od Tatr, przez Sudety, po Alpy i Himalaje). Doktorat z literatury o Tatrach uzyskał w 1965 roku. Jest prekursorem polskiej krytyki literatury górskiej (jako recenzent współpracował z „Taternikiem” i innymi czasopismami) oraz autorem licznych książek i setek rozpraw naukowych poświęconych różnym aspektom problematyki górskiej (między innymi uhonorowanej Nagrodą Burmistrza Zakopanego w 2017 roku obszernej monografii Literatura i Tatry. Studia i szkice). Przez wiele lat był przewodniczącym Rady Naukowej Muzeum Tatrzańskiego im. dra Tytusa Chałubińskiego w Zakopanem oraz przewodniczącym Rady Naukowej „Wierchów”. Wygłosił niezliczoną ilość wykładów i prelekcji naukowych oraz popularnonaukowych w kraju i za granicą. Był częstym prelegentem w Miejskiej Bibliotece Publicznej w Zakopanem podczas tak zwanych czwartków literackich oraz w różnych oddziałach Muzeum Tatrzańskiego, a także jurorem w Ogólnopolskim Konkursie Literackim im. Tadeusza Staicha w Zakopanem na wiersz o Tatrach. Jest twórcą i pierwszym redaktorem rocznika „Góry - Literatura - Kultura” oraz wspiera swym autorytetem Pracownię Badań Humanistycznych nad Problematyką Górską, działającą w Instytucie Filologii Polskiej Uniwersytetu Wrocławskiego. Bierze aktywny udział w międzynarodowych konferencjach dotyczących problematyki górskiej i należy do jej najwybitniejszych znawców środkowoeuropejskich. Jest inicjatorem interdyscyplinarnych badań nad problematyką górską zmierzających do stworzenia odrębnej subdyscypliny naukowej określanej jako mountain studies.

Janusz Majer — znany alpinista, himalaista i podróżnik. W latach 1980-1992 pełnił funkcję prezesa Klubu Wysokogórskiego w Katowicach, skupiającego w tamtym czasie najwybitniejszych polskich alpinistów i himalaistów (jego członkami byli między innymi: Jerzy Kukuczka, Krzysztof Wielicki, Ryszard Paw- 


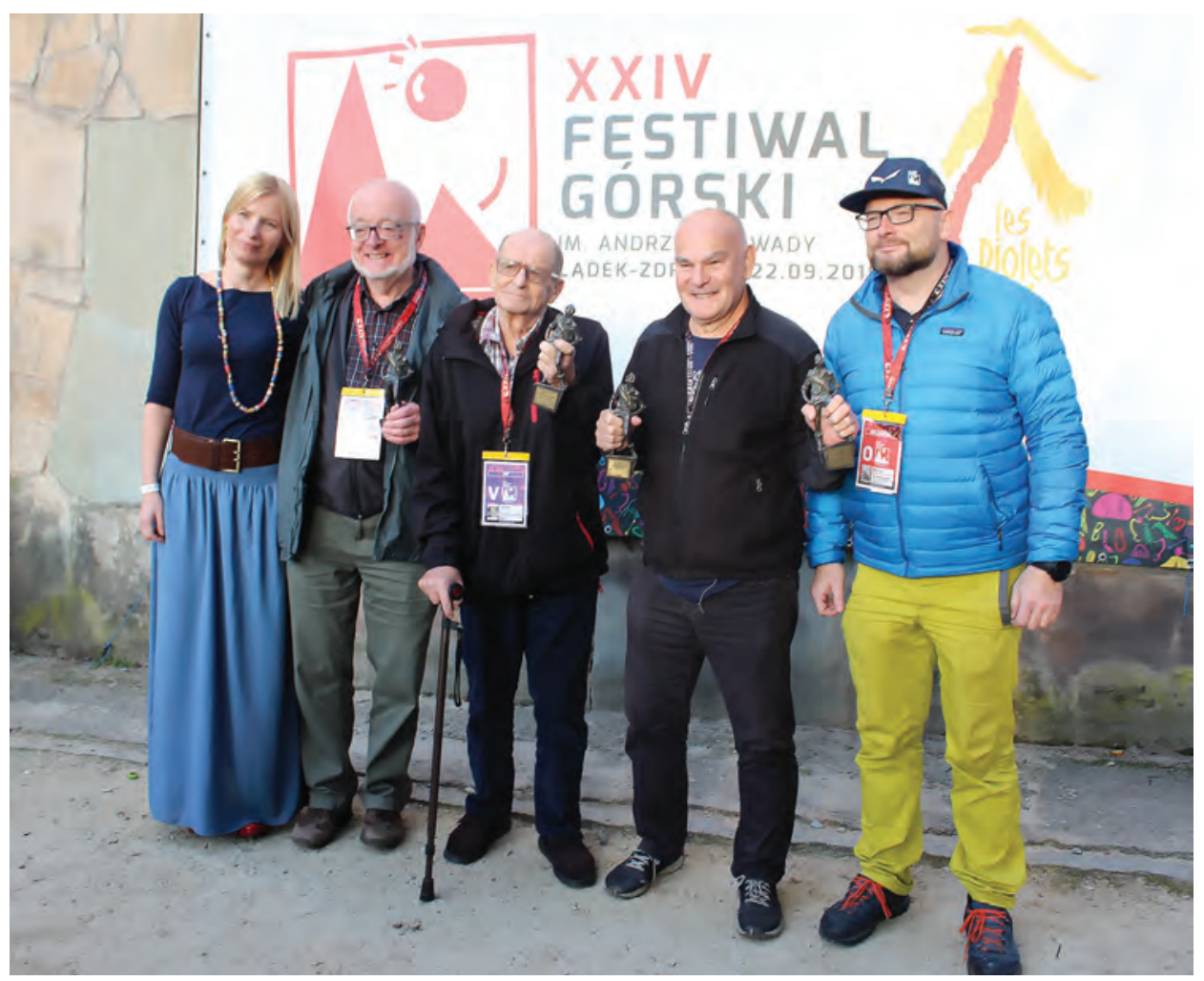

2. Laureaci nagród za popularyzację kultury górskiej wraz z organizatorami gali, Festiwal Górski im. Andrzeja Zawady, Lądek-Zdrój 2019, fot. Ewa Grzęda

łowski, Artur Hajzer). Był także wielokrotnym organizatorem Festiwalu Filmów Górskich w Katowicach $(1988,1990,1992)$ oraz jurorem górskich festiwali filmowych w Polsce i Europie (Teplice nad Metuji Festival - Czechy, Poprad Film Festival - Słowacja, Bansko Film Festival - Bułgaria, Explorer Film Festival — Polska, Łódź). Jest autorem wielu artykułów dotyczących wypraw wysokogórskich, publikowanych między innymi na łamach „Taternika”, „American Journal”, „The Alpine Journal” (na przykład Annapurna South Face — ascent and tragedy, „American Alpine Journal” 1989; oraz we współautorstwie z Jerzym Kukuczką Xixabangma 1987, „The Alpine Journal” 1990-1991). W latach 1987-1993 by1 wiceprezesem Polskiego Związku Alpinizmu oraz przewodniczącym Komisji Wspinaczki Wysokogórskiej PZA. Przez cztery i pół roku (od 23 listopada 2013 do 22 maja 2018 roku) był szefem programu Polskie Himalaje, którego częścią stał się program Polski Himalaizm Zimowy im. Artura Hajzera.

Wiesław Aleksander Wójcik — doktor nauk humanistycznych, przewodnik tatrzański i wieloletni redaktor naczelny rocznika „Wierchy”, będącego kontynuacją wydawanego od drugiej połowy XIX wieku „Pamiętnika Towarzystwa 
Tatrzańskiego". Od wielu lat jest niestrudzonym badaczem i popularyzatorem kultury górskiej, opublikował ponad sto cennych rozpraw naukowych i popularnonaukowych o tematyce górskiej. Jest również autorem licznych haseł encyklopedycznych dotyczących ludzi gór. Brał udział w wielu spotkaniach i konferencjach oscylujących wokół problematyki górskiej, wygłaszając prelekcje i odczyty wzbudzające żywe zainteresowanie słuchaczy. Jego opus magnum to pierwsza w Polsce monografia poświęcona słynnemu Sabale (miała już dwa wydania).

Jako pracownik Centralnego Ośrodka Turystyki Górskiej PTTK dba o regularną promocję książek i wydawnictw górskich, organizując liczne prelekcje i spotkania $z$ autorami. Jest członkiem wielu rad naukowych i redakcyjnych prestiżowych instytucji i czasopism związanych z górami. Ofiarnie współpracuje z Pracownią Badań Humanistycznych nad Problematyką Górską. 